\title{
CYTOPATHOLOGICAL EVALUATION OF THYROID BY FINE NEEDLE ASPIRATION CYTOLOGY AND CORRELATION WITH T3 T4 AND TSH LEVELS
}

\author{
Suman Poudel ${ }^{1}$, Sudeep Regmi ${ }^{2}$, Anita Shahi², Ashok Samdurkar ${ }^{3}$,
}

\section{ABSTRACT}

INTRODUCTION: Fine Needle Aspiration Cytology (FNAC) of the thyroid gland is now a well-established, first line diagnostic test for the evaluation of thyroid lesions. An FNA is performed along with Thyroid Function Test (TFT) profile to correlate cytology with hormonal function in symptomatic or asymptomatic patients.

MATERIALAND METHODS: Total of 117 cases of FNAC of thyroid lesions were selected who had undergone TFT profile. The lesions were evaluated cytologically and categorized according to Bethesda System of classification and correlated with TFT profile.

RESULTS: Out of 117 cases studied, the middle aged (20-49 years) females were most commonly affected by thyroid diseases. The predominant lesions cytologically were Benign Follicular Nodule (BFN) with frequency of 51.3\%.With respect to hormonal status most of the lesions were Euthyroid (53.8\%). The study showed no significant difference in mean of TFT profile with regard to various FNAC diagnoses.

CONCLUSION: The study showed that FNAC and TFT profile both are essential for the proper management of thyroid lesions and, there is no significant difference between FNAC diagnosis and mean TFT profile.

KEYWORDS: Fine Needle Aspiration Cytology (FNAC), Thyroid lesions, Bethesda system of classification, Thyroid Function Test (TFT)

1. Lecturer, Department of Pathology, Gandaki Medical College and Teaching Hospital, Pokhara Nepal

2. Assistant professor, Department of Pathology, Universal College of Medical Sciences \& Teaching Hospital, Bhairahawa, Nepal

3. Professor, Department of Pathology, Universal College of Medical Sciences \& Teaching Hospital, Bhairahawa, Nepal

\author{
For Correspondence \\ Dr. Suman Paudel \\ Lecturer, \\ Department of Pathology, \\ Gandaki Medical College and Teaching Hospital, \\ Pokhara, Nepal \\ Email: batigsu@gmail.com
}




\section{INTRODUCTION}

Fine Needle Aspiration Cytology (FNAC) of the thyroid gland is now a well-established and a first line diagnostic test for the evaluation of diffuse thyroid lesions. It bridges the gap between clinical evaluation and final surgical pathological diagnosis in majority of cases and helps to reduce unwanted surgeries. ${ }^{1}$ However, this is true only when the Fine Needle Aspiration (FNA) is performed by an experienced physician and the cytology is examined by an experienced pathologist. ${ }^{2}$ The basic morphologic unit of the thyroid gland is the follicle, composed of follicular cells which produce the hormones triiodothyronine (T3) and thyroxin (T4), which are in turn regulated by thyroid stimulating hormone (TSH), produced by the anterior pituitary gland. ${ }^{2}$ The levels of T3, T4 and TSH are assessed and thyroid lesions are categorized as hypothyroid, euthyroid or hyperthyroid conditions accordingly.

The purpose of the present study is to evaluate the various thyroid lesions by FNAC, classify them in different category based on The Bethesda System of Reporting Thyroid Cytology and to correlate those lesions with hormonal status of the same patient.

\section{MATERIAL AND METHODS}

It was a cross sectional descriptive study of 117 cases of Thyroid FNA during 18 months duration from January 2013 to June 2014 in the Department of Pathology and Biochemistry. All the patients presenting in our department with history of thyroid swelling and those who underwent thyroid function test in the department of biochemistry were examined in detail. FNAC was done following the standard procedure with 22 gauge needle by non-aspiration technique. From the sample obtained at least two dry and two wet smears were prepared and stained with Giemsa and Papanicolau stains respectively. In case of cystic lesions fluid was aspirated first followed by re-aspiration from the nodule. In difficult cases, image guided FNAC was done. The smears were evaluated by consultant pathologists and the final diagnoses of the FNAC were categorized according to The Bethesda system for reporting thyroid cytopathology.

The TFT profile was done in the Department of Biochemistry. The test was performed using ELISA kits from Human Gesellschaft fur Biochemica und Diagnostic MbH MaxPlanck-Ring 21, D-6205 Wiesbaden, Germany Serozyme ELISA. The test was performed on Erba Lisa Scan II. The data was collected and evaluated with respect to thyroid lesions.

The cytomorphological details, FNAC Diagnosis and TFT reports data were entered in the Microsoft Excel 2010 and study variables were statistically analyzed by "Statistical Package for Social Service" (SPSS) 20.0

\section{RESULTS}

117 patients underwent FNAC of thyroid lesions along with TFT profile during this time interval of 18 months. A distribution of thyroid lesions with respect to age, sex, FNAC diagnosis and correlation with TFT was evaluated in this study.

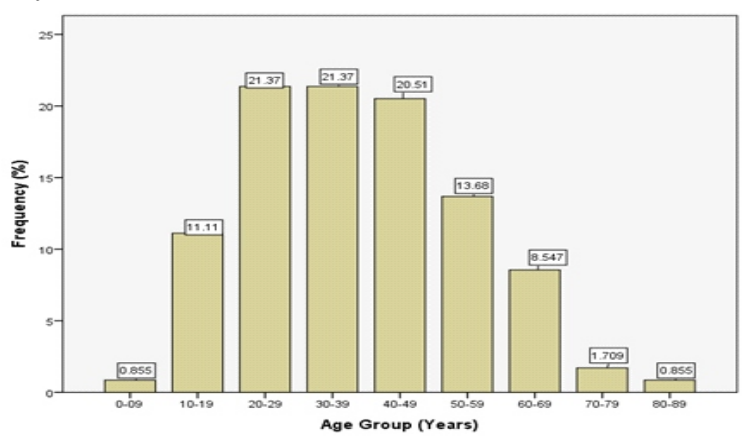

Figure 1: Age wise distribution of thyroid lesions $(n=117)$

The most common age group affected was 20-29 and 30-39 each with $21.37 \%$ followed by $40-49$ with frequency of $20.51 \%$. The least affected age group was below 10 years and above 80 years of age each comprising $0.86 \%$. The mean age of the patients presented with thyroid lesion was $37.91 \pm 15.15$ years $(\mathrm{x} \pm \mathrm{SD})$. The distribution of female was with frequency of $89.74 \%$ and that of male was $10.26 \%$ out of 117 cases. (Fig. 1)

Table 1: Cross tabulation between Diagnosis and Thyroid function test $(n=117)$

\begin{tabular}{|c|c|c|c|c|c|c|c|}
\hline & \multicolumn{5}{|c|}{ THROID FUNCTION TEST } & \multirow{3}{*}{$\begin{array}{c}\text { Total } \\
6 \\
\end{array}$} \\
\hline & & \multirow{2}{*}{-} & \multirow{2}{*}{ 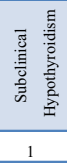 } & \multirow[t]{2}{*}{ 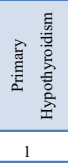 } & \multirow{2}{*}{ 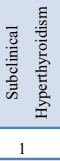 } & \multirow{2}{*}{ 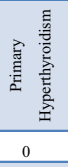 } & \\
\hline \multirow{20}{*}{ 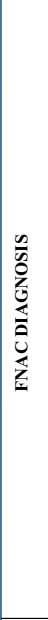 } & \multirow{2}{*}{ Non Diagnostic } & & & & & & \\
\hline & & $2.6 \%$ & $0.9 \%$ & $0.9 \%$ & $0.9 \%$ & $0.0 \%$ & $5.1 \%$ \\
\hline & \multirow{2}{*}{ Benign, BFN } & 40 & 3 & 6 & 6 & 5 & 60 \\
\hline & & $34 . \%$ & $2.6 \%$ & $5.1 \%$ & $5.1 \%$ & $4.3 \%$ & $51.3 \%$ \\
\hline & \multirow{2}{*}{ Benign, LT } & 6 & 4 & 14 & 1 & 4 & 29 \\
\hline & & $5.1 \%$ & $3.4 \%$ & $12 . \%$ & $0.9 \%$ & $3.4 \%$ & $24.8 \%$ \\
\hline & \multirow[b]{2}{*}{ Benign, SAT } & 2 & 0 & 0 & 0 & 3 & 5 \\
\hline & & $1.7 \%$ & $0.0 \%$ & $0.0 \%$ & $0.0 \%$ & $2.6 \%$ & $4.3 \%$ \\
\hline & \multirow{2}{*}{$\mathrm{FN} / \mathrm{SFN}$} & 7 & 0 & 0 & 0 & 1 & 8 \\
\hline & & $6.0 \%$ & $0.0 \%$ & $0.0 \%$ & $0.0 \%$ & $0.9 \%$ & $6.8 \%$ \\
\hline & \multirow{2}{*}{ FN, HCT } & 1 & 0 & 0 & 0 & 0 & 1 \\
\hline & & $0.9 \%$ & $0.0 \%$ & $0.0 \%$ & $0.0 \%$ & $0.0 \%$ & $0.9 \%$ \\
\hline & \multirow{2}{*}{ Suspicious of PTC } & 2 & 1 & 1 & 0 & 1 & 5 \\
\hline & & $1.7 \%$ & $0.9 \%$ & $0.9 \%$ & $0.0 \%$ & $0.9 \%$ & $4.3 \%$ \\
\hline & \multirow{2}{*}{ Malignant, PTC } & 1 & 0 & 0 & 0 & 0 & 1 \\
\hline & & $0.9 \%$ & $0.0 \%$ & $0.0 \%$ & $0.0 \%$ & $0.0 \%$ & $0.9 \%$ \\
\hline & \multirow{2}{*}{ Malignant, ACT } & 1 & 0 & 0 & 0 & 0 & 1 \\
\hline & & $0.9 \%$ & $0.0 \%$ & $0.0 \%$ & $0.0 \%$ & $0.0 \%$ & $0.9 \%$ \\
\hline & \multirow{2}{*}{ Benign, Others } & 0 & 1 & 0 & 0 & 0 & 1 \\
\hline & & $0.0 \%$ & $0.9 \%$ & $0.0 \%$ & $0.0 \%$ & $0.0 \%$ & $0.9 \%$ \\
\hline & \multirow[b]{2}{*}{ TOTAL } & 63 & 10 & 22 & 8 & 14 & 117 \\
\hline & & $53.8 \%$ & $8.5 \%$ & $18.8 \%$ & $6.8 \%$ & $12.0 \%$ & $100 \%$ \\
\hline
\end{tabular}


BFN: Benign Follicular Nodule, LT: Lymphocytic Thyroiditis, SAT: Subacute Thyroiditis, FN: Follicular Neoplasm, SFN: Suspicious of Neoplasm, HCT: Hurthle Cell Tumor, PTC: Papillary Thyroid Carcinoma, ACT: Anaplastic Carcinoma Thyroid.

Euthyroid condition was most commonly seen in BFN 34\% of total cases followed by FN/SFN $6.0 \%$. Primary hypothyroidism was seen predominantly in LT $12 \%$ followed by BFN $5.1 \%$. LT $3.4 \%$ showed subclinical hypothyroidism whereas BFN 4.3\%, LT 3.4\% and SAT 2.6\% showed primary hypothyroidism. Also BFN 5.1\% showed subclinical hyperthyroidism. (Table 1)

Table 2: One way ANOVA of TFT Profile in comparison to FNAC Diagnosis $(n=117)$

\begin{tabular}{|c|c|c|c|c|c|c|}
\hline \multicolumn{2}{|c|}{} & $\begin{array}{c}\text { Sum of } \\
\text { Squares }\end{array}$ & Df & $\begin{array}{c}\text { Mean } \\
\text { Square }\end{array}$ & F & Sig, \\
\hline \multirow{4}{*}{ fT3 } & Between Groups & 6.023 & 9 & .669 & .402 & .932 \\
\cline { 2 - 7 } & Within Groups & 178.167 & 107 & 1.665 & & \\
\cline { 2 - 7 } & Total & 184.190 & 116 & & & \\
\hline \multirow{4}{*}{ fT4 } & Between Groups & .940 & 9 & .104 & .313 & .969 \\
\cline { 2 - 7 } & Within Groups & 35.659 & 107 & .333 & & \\
\cline { 2 - 7 } & Total & 36.599 & 116 & & & \\
\hline \multirow{3}{*}{ TSH } & Between Groups & 3040.084 & 9 & 337.787 & 1.577 & .131 \\
\cline { 2 - 7 } & Within Groups & 22917.974 & 107 & 214.187 & & \\
\cline { 2 - 7 } & Total & 25958.058 & 116 & & & \\
\hline
\end{tabular}

With the confidence interval of $95 \%$ and $p<0.05$, there was no significant difference $(p>0.05)$ of the mean levels of $\mathrm{T} 3$ $(p=0.932)$, T4 $(p=0.969)$ and TSH $(p=0.131)$ between and within the various groups of FNAC Diagnosis.(Table 2).

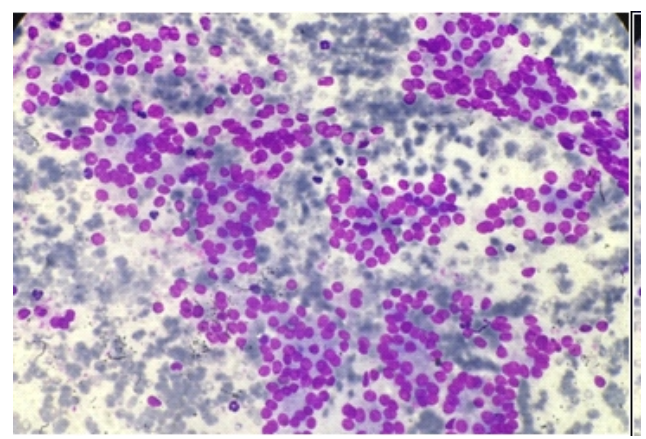

Photomicrograph 1: High Cellularity in Follicular Neo plasm

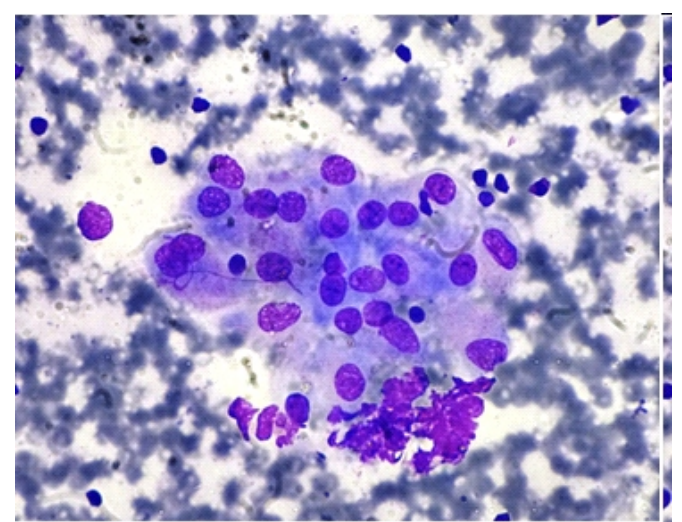

Photomicrograph 2: Lymphocytes impinging into follicles along with hurthle cells in Hashimoto Thyroiditis (Giemsa 400X

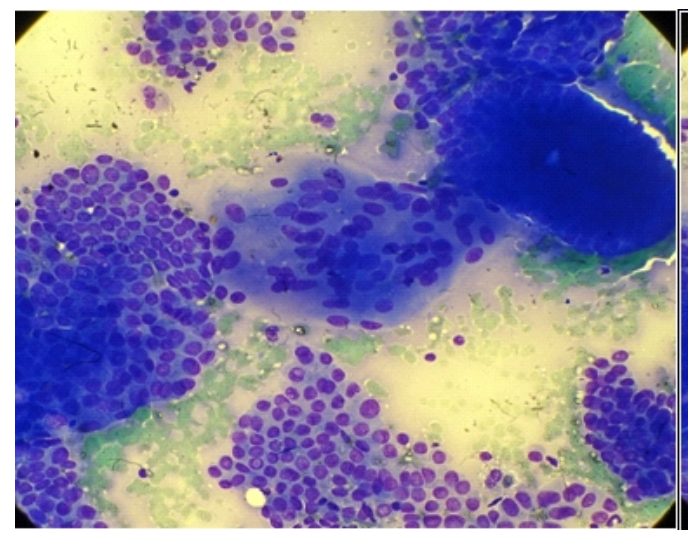

Photomicrograph 3: Nuclear overcrowding with Giant cell and few intranuclear cytoplasmic inclusions in PTC (Giemsa 100X)

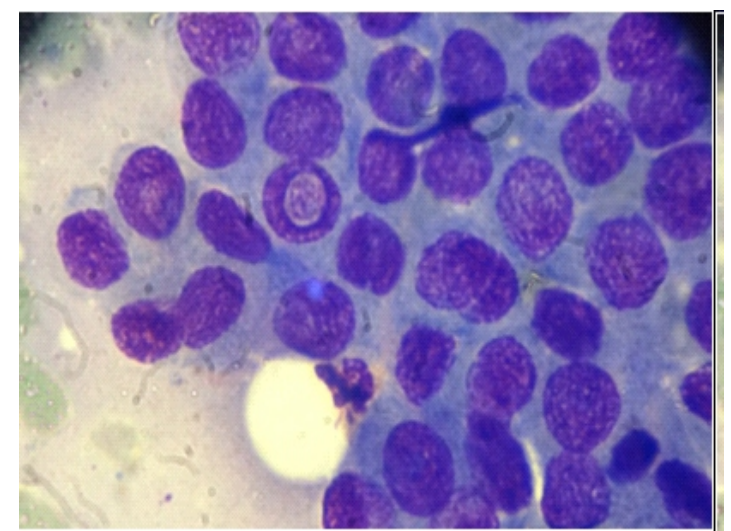

Photomicrograph 4: Intranuclear cytoplasmic inclusion in PTC (Giemsa 1000X) 


\section{DISCUSSION}

FNAC is usually the first line of investigation and other investigations like ultrasonography (USG) examination, TFT, thyroid scan, and antibody levels are done subsequently with an aim to select the patients who require surgery and those who can be managed conservatively. In the present study, the age of the patients with thyroid lesion range from 9 to 81 years with mean age of $37.91 \pm 15.15$ years. Similar figures are noted in the study performed by Yang et al. ${ }^{4}$.According to Patel et al. ${ }^{5}, 20-50$ years is the most common age group that present with thyroid lesion which is similar to our study. In our study, the most common age group that presented with thyroid lesion was 20-49 years comprising of $63.3 \%$.

The study showed that thyroid lesions are common in females with F: M ratio of 8.75:1. This is justified by similar findings stated by Yang et al. ${ }^{6}$, Sood et al. ${ }^{7}$, Jaragh et al. ${ }^{8}$ and Renshaw et al. .

As stated by Mahar et al. ${ }^{10}$ and Sood et al. ${ }^{7}$, BFN was the most common thyroid lesions followed by LT which had similarities to the present study. BFN corresponded to nodular goiter, adenomatoid nodule and colloid goiter. Follicular neoplasm comprised of $6.8 \%$, malignant lesions were relatively less in number. PTC was the most common malignant lesion in our study. It comprised of $85.2 \%$ of total malignant cases which is similar to the study conducted by Sinna et al. ${ }^{1}$ which showed that it comprised of $72.4 \%$ of malignant cases. To come to the diagnosis of FNA thyroid lesions, various cytomorphological variables like cellularity, pattern, and nuclear morphology of follicular cells, hurthle cells, foam cells, giant cells, inflammatory infiltrate and background were evaluated.

The lesions categorized as Non Diagnostic, which comprised of $5.1 \%$, were predominantly sparsely cellular with scattered or no follicular cells. They had only foam cells, scanty or absent colloid and hemorrhagic background.Similar morphology has been described by Cibas et al. ${ }^{11}$ for categori zation of Non Diagnostic lesions. Such lesions were advised for re-aspiration preferably under image guidance from solid part if present. The study performed by Ersoz et al. ${ }^{12}$ is similar to our study which showed low cellularity in benign conditions and high cellularity in follicular neoplasm (Photomicrograph 1) and malignant conditions like PTC.

Benign appearing hurthle cells with eccentrically placed nuclei and abundant eosinophilic granular cytoplasm was noted predominantly in Lymphocytic or Hashimoto's Thyroiditis (Photomicrograph 2). The nuclear morphology with nuclear grooving and INCI (photomicrograph 3 and 4) were present in all the cases of Suspicious of Papillary Thyroid Carcinoma (PTC) (4.3\%) and malignant PTC (0.9\%). Similar features were explained by Bhambhani et al. ${ }^{13}$ who gave emphasis to nuclear grooving and INCIs for the diagnosis of PTC. According to Orell and Sterrett ${ }^{14}$, it is highly suspicious for PTC, if the smears contain nuclear groove in more than $20 \%$ of cells and INCIs in 5\%, but still it is not significant. Besides cellularity, nuclear grooving and INCI, pleomorphism, pattern, nucleoli, foam cells are also statistically significant for the diagnosis of thyroid lesions. However, variables like hurthle cells, giant cells, granuloma and inflammatory cells are non-significant for the FNA diagnosis.

The hormonal evaluation of patients with thyroid lesions is essential for the proper management of the patients. The most common cause of euthyroid was BFN constituting $34 \%$ in our study, similar to the study conducted by Sang et al. ${ }^{15}$ And this showed that there is no correlation between FNAC and TFT profile. Most of the benign and malignant neoplasms including FN/SFN, PTC and ACT were euthyroid. Primary hypothyroidism was commonly seen in cases of LT comprising of $12 \%$. Gayathri B et al. ${ }^{16}$ also had explained LT as the most common cause of hypothyroidism which is in concordance with our study. Primary hyperthyroidism was noted in benign conditions like BFN, LT and SAT with frequency of $4.3 \%, 3.4 \%$ and $2.6 \%$ respectively. The hyperplastic nodule in MNG, early phase of HT and SAT all were the reasons for features of primary hyperthyroidism in our study, which is similar to study done by Chandanwale et al. ${ }^{17}$ One way analysis of variance (ANOVA) was done to determine whether T3, T4 and TSH concentration vary across the various groups of FNA Diagnosis.

With the confidence interval of $95 \%$ and $p<0.05$ there was no significant statistical difference of the mean levels of T3 (0.932), T4 (0.969) and TSH (0.131) between and within the various groups of FNA Diagnosis. So, different FNAC diagnosis can have same TFT profile or the hormonal level may vary within the same group of FNAC diagnosis. As for example, the hormonal levels in BFN are not constant and range from hypothyroid to euthyroid to hyperthyroid in our study. So, there is no correlation between FNAC diagnosis and TFT profile. This finding is in concordance with the study done by Sang et al. (15) which showed that there is no significant difference between mean TFT profile and various FNAC diagnosis group. However, other studies conducted by Kini et al. ${ }^{18}$ and Chehade et al. ${ }^{19}$ showed significant difference in mean TFT profile in various FNAC diagnosis which is in discordance with our present study.

\section{CONCLUSION}

In the study, the most common thyroid lesion was BFN and most affected age group was 20-50 years with female predominance. For the diagnosis of PTC, nuclear grooving, INCIs along with other supporting features are required. The study showed that there is no significant difference between 
mean T3, T4 and TSH profile and various groups of FNAC diagnosis. The FNAC diagnosis alone cannot be used to predict thyroid function and preferably serum T4, T3 and TSH concentrations should be evaluated separately for the proper management of thyroid lesions.

Hence, we conclude that FNAC diagnosis and TFT profile are two independent variables and there is no correlation between them. And, both should be done simultaneously for proper management of the thyroid lesion.

\section{REFERENCES}

1. Sinna EA, Ezzat N. Diagnostic accuracy of fine needle aspiration cytology in thyroid lesions. J Egypt Natl Cancer Inst. 2012 Jun;24(2):6370. http://dx.doi.org/10.1016/j.jnci.2012.01.001 PMid:23582597

2. Holleman F, Hoekstra JB, Ruitenberg HM. Evaluation of fine needle aspiration (FNA) cytology in the diagnosis of thyroid nodules. Cytopathol Off J Br Soc Clin Cytol. 1995 Jun;6(3): 16875.

http://dx.doi.org/10.1111/j.1365-2303.1995.tb00470.x

3. Giuffrida D, Gharib H. Controversies in the management of cold, hot, and occult thyroid nodules. Am J Med. 1995 Dec;99(6):64250.

http://dx.doi.org/10.1016/S0002-9343(99)80252-6

4. Yang J, Schnadig V, Logrono R, Wasserman PG. Fine-needle aspiration of thyroid nodules: a study of 4703 patients with histologic and clinical correlations. Cancer. 2007 Oct 25;111(5):30615. http://dx.doi.org/10.1002/cncr.22955 PMid: 17680588

5. Patel MM, Patel KK, Kaptan KR, Italiya SL, Saini GG singh. Fine needle aspiration cytology as a first line investigation in thyroid lesions. Natl JMed Res. 2013;3(2):10610.

6. Yang GCH, Stern CM, Messina AV. Cystic papillary thyroid carcinoma in fine needle aspiration may represent a subset of the encapsulated variant in WHO classification. Diagn Cytopathol. 2010 Oct;38(10):7216. PMid:20024942

7. Sood N, Nigam JS. Correlation of fine needle aspiration cytology findings with thyroid function test in cases of lymphocytic thyroiditis. JThyroid Res. 2014;2014:430510. http://dx.doi.org/10.1155/2014/430510 PMid:24808970 PMCid:PMC3997907

8. Jaragh M, Carydis VB, MacMillan C, Freeman J, Colgan TJ. Predictors of malignancy in thyroid fine-needle aspirates "cyst fluid only"cases: can potential clues of malignancy be identified? Cancer. 2009 Oct 25;117(5):30510. http://dx.doi.org/10.1002/cncy.20041
9. Renshaw AA. Focal features of papillary carcinoma of the thyroid in fine-needle aspiration material are strongly associated with papillary carcinoma at resection. Am J Clin Pathol. 2002 Aug;118(2):20810. http://dx.doi.org/10.1309/QDLD-FTY3M8ED-CX6U

PMid:12162679

10. Mahar SA, Husain A, Islam N. Fine needle aspiration cytology of thyroid nodule: diagnostic accuracy and pitfalls. J Ayub Med Coll AbbottabadJAMC.2006Dec;18(4):269. PMid:17591005

11. Cibas ES, Ali SZ, NCI Thyroid FNA State of the Science Conference. The Bethesda System For Reporting Thyroid Cytopathology. Am JClin Pathol. 2009 Nov;132(5):65865. http://dx.doi.org/10.1309/AJCPPHLWMI3JV4LA PMid:19846805

12. Ersöz C, Firat P, Uguz A, Kuzey GM. Fine-needle aspiration cytology of solitary thyroid nodules: how far can we go in rendering differential cytologic diagnoses? Cancer. 2004 Oct 25;102(5):3027. http://dx.doi.org/10.1002/cncr.20610 PMid:15376197

13. Bhambhani S, Kashyap V, Das DK. Nuclear grooves. Valuable diagnostic feature in May-Grünwald-Giemsa-stained fine needle aspirates of papillary carcinoma of the thyroid. Acta Cytol. 1990 Dec;34(6):80912. PMid:1701601

14. Svante R. Orell, Gregory F. Sterrett. Fine Needle Aspiration Cytology. 5thed.118-155.

15. Sang CK, Kigondu CS, Muchiri L. Correlation between cytology and thyroid function test. East Afr Med J. 2006 Oct;83(10):5338. PMid:17310678

16. Gayathri B, Kalyani R, Harendra KM, Krishna PK. Fine needle aspiration cytology of Hashimoto's thyroiditis - A diagnostic pitfall with review of literature. J Cytol Indian Acad Cytol. 2011 Oct;28(4):2103. http://dx.doi.org/10.4103/0970-9371.86353 PMid:22090699

17. Chandanwale S, Singh N, Kumar H. Clinicopatholological correlation of thyroid nodules. Int J Pharm Biomed Sci. 2012;3(3):97102.

18. Kini U, Buch A, Bantwal G. Role of FNA in the medical management of minimally enlarged thyroid. Diagn Cytopathol. 2006 Mar;34(3):196200. http://dx.doi.org/10.1002/dc.20415 PMid:16470863

19. Chehade JM, Lim W, Silverberg AB, Mooradian AD. The incidence of Hashimoto's disease in nodular goitre: the concordance in serological and cytological findings. Int J Clin Pract. 2010Jan;64(1):2933 http://dx.doi.org/10.1111/j.1742-1241.2008.01942.x PMid:20089015 